\title{
Stretched Lens Array (SLA) Solar Electric Propulsion (SEP) Space Tug: SLA-SEP Offers Multi-Billion-Dollar Savings Delivering Lunar Exploration Cargo
}

\author{
Mark O’Neill ${ }^{1}$, Michael Piszczor ${ }^{2}$, Henry Brandhorst ${ }^{3},{\text { Christian } \text { Carpenter }^{4}, \text { A.J. McDanal }}^{1}$ \\ 1. ENTECH, Inc., Keller, TX 76248 USA \\ 2. NASA Glenn Research Center, Cleveland, OH 44135 USA \\ 3. Auburn University, Auburn, AL 36849 USA \\ 4. Aerojet, Redmond, WA 98052 USA
}

\begin{abstract}
For the past three years, our team has been developing, refining, and maturing a unique solar array technology known as the Stretched Lens Array (SLA). SLA is a costeffective, modular, scalable, and mass-producible space power technology, offering an unprecedented portfolio of near-term performance metrics, including $>300 \mathrm{~W} / \mathrm{m}^{2}$ power density, $>300 \mathrm{~W} / \mathrm{kg}$ specific power, $>80 \mathrm{~kW} / \mathrm{m}^{3}$ stowed power, and $300-600 \mathrm{~V}$ operating voltage. In addition, SLA enables super-shielding of the solar cells for excellent radiation hardness at low mass penalty. These attributes make SLA ideally suited for reusable Solar Electric Propulsion (SEP) space tugs, especially those which haul cargo from low earth orbit (LEO) to the Moon. NASA's lunar exploration program will require hundreds of metric tons (MT) of cargo to be delivered to the Moon in the 2020 timeframe. As shown in this paper, SLA-SEP tugs will offer multi-billion-dollar savings over conventional chemically fueled lunar cargo delivery approaches.
\end{abstract}

\section{INTRODUCTION AND BACKGROUND}

ENTECH, NASA, and other team members have been developing refractive photovoltaic concentrator systems for producing space power from sunlight since the middle 1980's [1]. The first such technology developed and successfully flown in space was the point-focus mini-dome lens array, shown in Fig. 1. This array used mechanically

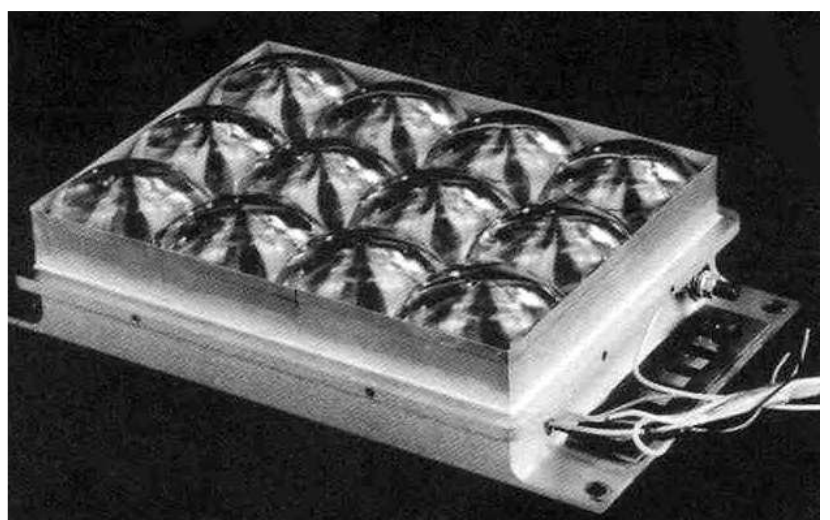

Fig. 1. Mini-Dome Lens Array for the PASP-Plus Flight Test (1994-1995). stacked GaAs/GaSb cells from Boeing in the focal point of ENTECH's silicone mini-dome Fresnel lens concentrators. The lenses were coated with a multi-layer oxide coating to protect the silicone lens material from solar ultraviolet (UV) radiation and monatomic oxygen (AO). The mini-dome lens array in Fig. 1 flew in 1994-95 on the NASA/USAF year-long PASP-Plus flight test in a very high-radiation elliptical orbit $(363 \mathrm{~km}$ by $2,550 \mathrm{~km}$ at 70 -degree inclination). Of the 12 advanced photovoltaic array types included on PASP-Plus, the mini-dome lens provided the highest performance and the least degradation [2].

After the mini-dome lens array success, ENTECH, NASA, and other team members next developed the line-focus arched lens array, which evolved into the SCARLET array that performed flawlessly for the full thirty-eight-month mission on NASA's Deep Space 1 probe, shown in Fig. 2. SCARLET (acronym for Solar Concentrator Array using Refractive Linear Element Technology) employed silicone Fresnel lens material made by $3 \mathrm{M}$ using a high-speed continuous process. ENTECH laminated this silicone lens material to 75-micron-thick ceria-doped glass arches, which provided support and UV protection for the lenses. Monolithic triple-junction (GalnP/GaAs/Ge) cells were placed in the focal lines of the SCARLET lenses. The SCARLET array powered both the spacecraft and the ion engine on Deep Space 1 and performed as predicted on this highly successful mission [3].

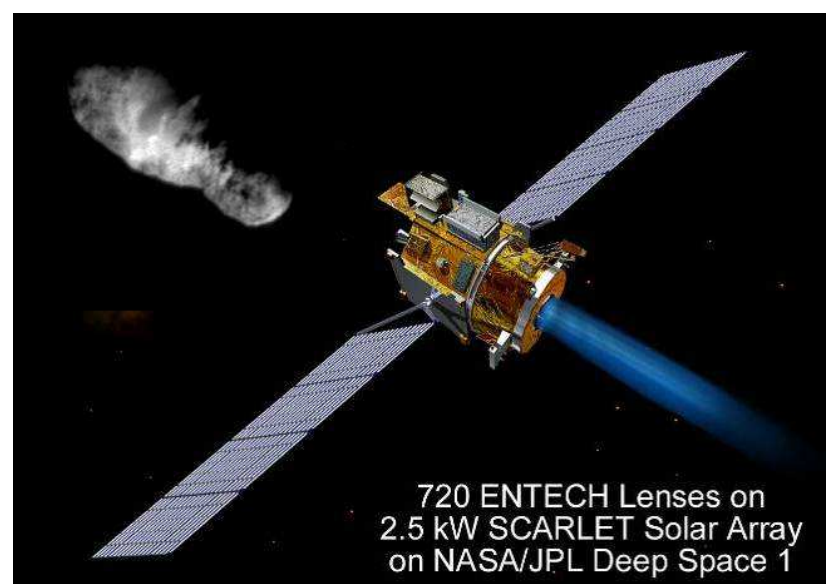

Fig. 2. SCARLET Array on NASA/JPL Deep Space 1 Probe (1998-2001). 
Shortly after the SCARLET array delivery, ENTECH discovered a simpler approach to deploy and support the line-focus silicone lenses, thereby eliminating the fragile, bulky, and expensive glass arches used on SCARLET.

The new approach uses simple lengthwise tensioning of the lens material between end arches for lens deployment and support on orbit, as shown in Fig. 3. Called the Stretched Lens Array (SLA), the new ultra-light concentrator array also enables a very compact stowage volume for launch [4]. SLA is compatible with a variety of space array platforms, from small unfolding rigid-panel wings to large deployable flexible-blanket wings. Of all the platforms evaluated for SLA to date, the lightest and most compact is ATK Space Systems' SquareRigger. Originally developed for the Air Force Research Lab as a platform for thin-film solar cell arrays in space, SquareRigger is an even better match for the high-efficiency, ultra-light SLA technology [5].

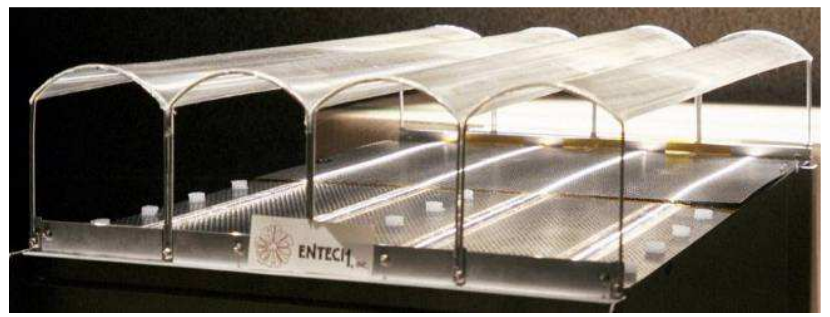

Fig. 3. Stretched Lens Array (SLA) Prototype.

\section{STRETCHED LENS ARRAY SQUARERIGGER (SLASR)}

SLASR offers an amazingly compact stowed volume and an extremely light-weight deployed platform for the flexible-blanket version of SLA for high-power space missions, as shown schematically in Fig. 4. For launch, SLASR's carbon composite structural tubes stow in a very compact volume, with the two folded and interleaved blankets of lenses and radiator sheets (containing the solar cell circuits) nested between the tubes. On orbit, the tubes automatically deploy to form rectangular "bay" structures, each about $2.5 \mathrm{~m} \times 5.0 \mathrm{~m}$ in size. After the bay tubular frame structure deploys and locks, the lens and radiator blankets are automatically pulled across the frame

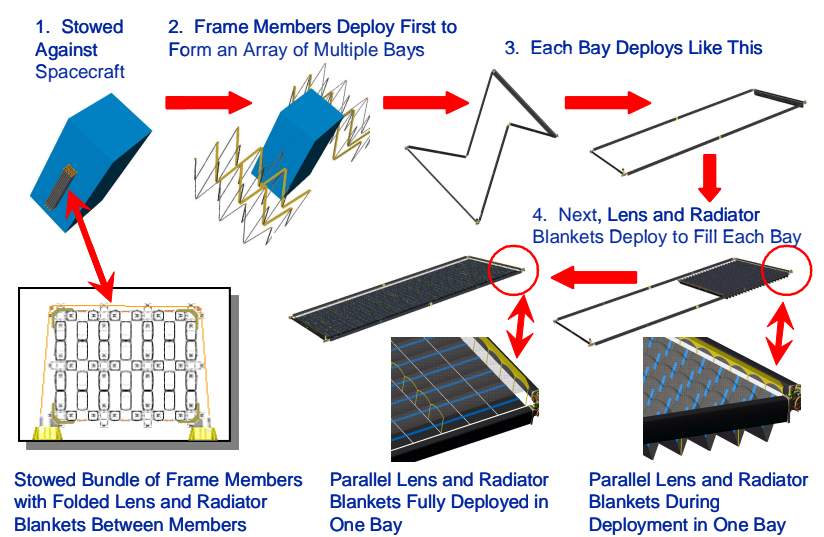

Fig. 4. Stretched Lens Array SquareRigger (SLASR) Schematic. to form the deployed solar array. Recently, a full-scale SLASR bay has been fabricated and successfully deployed, as shown in Fig. 5.

Multiple bays of the $2.5 \mathrm{~m} \times 5.0 \mathrm{~m}$ size shown in Fig. 5 are employed to form large solar array wings for high-power space missions. Since each bay provides about $4 \mathrm{~kW}$ of power on orbit, two 12-bay wings will provide about $100 \mathrm{~kW}$ on orbit. For this $100 \mathrm{~kW}$ point design, Fig. 6 shows the mass breakdown for a typical geostationary Earth orbit (GEO) mission. The lens and radiator blankets comprise about $70 \%$ of the total wing-level mass, which corresponds to only $0.85 \mathrm{~g} / \mathrm{m}^{2}$ for this large array size.

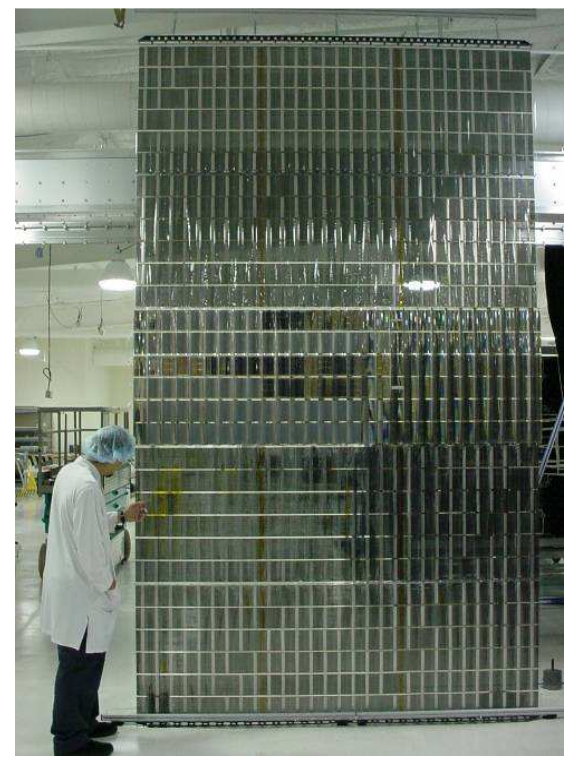

Fig. 5. Stretched Lens Array (SLA) Prototype.

Mass Breakdown for $100 \mathrm{~kW}$ Stretched Lens Array SquareRigger (SLASR) for Current Technology and Normal GEO Radiation Shielding

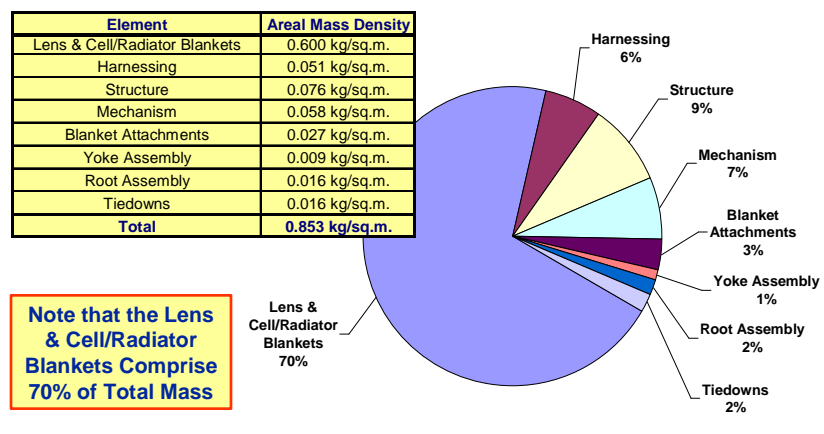

This mass breakdown is for a near-term $100 \mathrm{~kW}$ SLASR with today's $30 \%$ efficient cells and today's lens and radiator thicknesses

Fig. 6 Mass Breakdown for 100 kW SLASR Array.

\section{SOLAR ELECTRIC PROPULSION (SEP) SPACE TUG}

Our team recently conducted a study of a SLASR-power Solar Electric Propulsion (SEP) space tug for lunar cargo transportation. The tug and mission are outlined in Fig. 7. The tug is designed for five round trips from LEO to lunar orbit, where a chemically fueled lunar lander will be 
released from the tug to deliver the cargo to the surface. Each round trip will take less than one year and will result in 22 MT of cargo delivery to the lunar surface. Thus, 110 MT of cargo will be delivered over the five year mission. Five launches will be needed to deliver all the required materials to LEO for the five-year mission. The same solar array and tug will be reused five times over the five-year mission. A nominal $600 \mathrm{~kW}, 2,000 \mathrm{~m}^{2}$ SLASR array will be needed to direct-drive the Hall-effect thrusters, which use Xenon as their propellant.

The SLASR array for this mission will require more shielding on the solar cells than for a normal GEO mission, since the SEP tug will spiral slowly through the Earth's radiation belts during each trip from LEO to the Moon and back. To determine the optimal amount of shielding, the total mission radiation environment must be defined. Since the electron and proton radiation fluences vary widely with orbital altitude and inclination, the trajectory information must first be calculated. We have generated a simple spreadsheet model based on orbital energetics to estimate the spiral trajectories, in addition to other relevant mission parameters.

Table 1 shows the typical inputs and outputs of this model. Each round trip from LEO to the Moon includes an outbound spiral trajectory of the "heavy" tug (with lunar lander, lunar lander chemical fuel, cargo, and Xenon propellant for the complete round trip) and a return trip of the "light" tug (without lunar lander, lunar lander chemical fuel, cargo, and Xenon used during the outbound trip). The minimum days in sunlight for both the outbound and inbound trips can be estimated with the rocket equation, but this ignores two important effects: the Earth's shadowing of the array during a portion of each spiraling orbit and residual atmospheric drag in LEO. These two important effects are treated in our spreadsheet model by a stepwise integration over time to calculate the actual spiral trajectories (the real days in Table 1).

Drag is modeled based on the worst-case atmospheric density $(\rho)$ versus altitude curve from the European Space Agency's outstanding online tool known as SPENVIS (www.spenvis.oma.be). The orbital-average projected

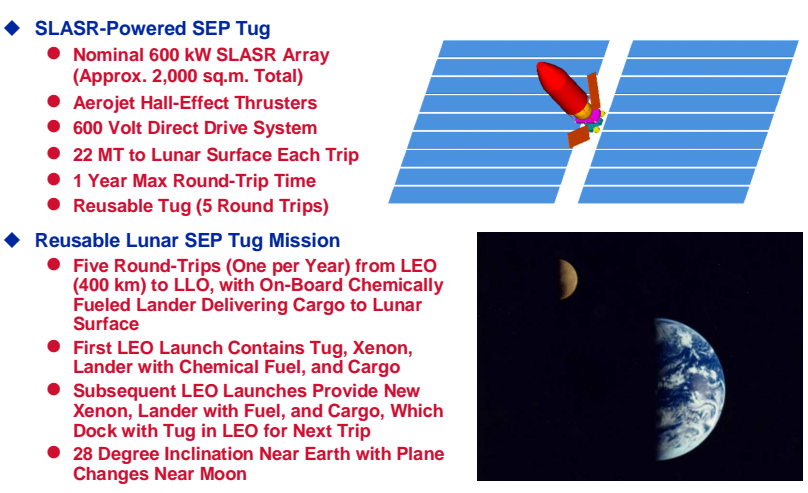

Fig. 7. SLASR-Powered Solar Electric Propulsion (SEP) Reusable Lunar Cargo Tug and Mission Description.

area $(A)$ of the rotating solar array is combined with a worst-case drag coefficient $\left(C_{D}\right)$ of 4 , and with the local orbital velocity $(\mathrm{V})$ to complete the drag calculation using the usual formula:

$$
D=\frac{1}{2} \rho V^{2} C_{D} A
$$

Since drag acts on the solar array for the full orbit while the Hall-effect thrusters only provide thrust for the illuminated portion of each orbit, the orbit-average thrust to drag ratio is a critical parameter. Fig. 8 shows this ratio as a function of altitude with solar array performance parameterized in terms of areal power density. Note that array performance is important, especially for relatively low starting altitudes, since the thrust to drag ratio must be obviously be well over 1.0 to enable the tug to move outward rather than falling back to Earth.

With drag and Earth shadowing properly treated, Fig. 9 shows the calculated outbound trajectory from LEO to low lunar orbit (LLO) for the SLASR-powered SEP tug described in Fig. 7 and Table 1 above. The return spiral has the same curve shape as Fig. 9 , but takes only $1 / 6^{\text {th }}$ as long because of the lighter mass of the returning tug.

The trajectory information for all five round trips is used to calculate the equivalent $1 \mathrm{MeV}$ electron fluences as a

\begin{tabular}{|c|c|c|c|c|c|c|c|c|c|c|}
\hline \multicolumn{11}{|c|}{ Input Parameters } \\
\hline Power & $\begin{array}{c}\text { Array Specific } \\
\text { Power }\end{array}$ & ISP SEP & $\begin{array}{c}\text { SEP Power } \\
\text { Efficiency }\end{array}$ & ISP Chem & $\begin{array}{l}\text { SEP Delta V } \\
\text { LEO to LLO }\end{array}$ & $\begin{array}{l}\text { Chem Delta V } \\
\text { LLO to Surface }\end{array}$ & Cargo & $\begin{array}{l}\text { Mass Ratio } \\
\text { LLO to } \\
\text { Surface }\end{array}$ & $\begin{array}{c}\text { Array Areal } \\
\text { Power }\end{array}$ & Array Area \\
\hline $600,000 \mathrm{~W}$ & $300 \mathrm{~W} / \mathrm{kg}$ & $2,500 \mathrm{Sec}$ & $60 \%$ & $400 \mathrm{Sec}$ & $8,000 \mathrm{~m} / \mathrm{s}$ & $2,000 \mathrm{~m} / \mathrm{s}$ & $22,000 \mathrm{~kg}$ & 1.67 & $300 \mathrm{~W} / \mathrm{sq} . \mathrm{m}$. & 2000 sq.m. \\
\hline
\end{tabular}

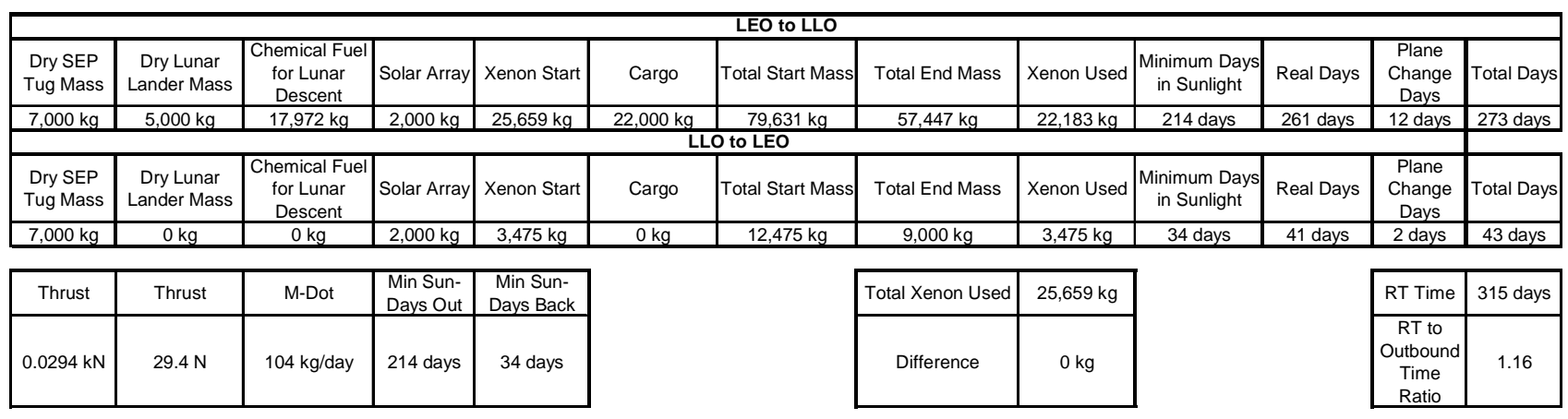

Table 1. SLASR-Powered Solar Electric Propulsion (SEP) Lunar Tug Spreadsheet Model Typical Inputs and Results. 
SEP Thrust to Solar Array Drag Ratio for $2,500 \mathrm{sec}$ ISP Direct-Drive Thruster Using Solar Max Atmospheric Density Data from SPENVIS (http://www.spenvis.oma.be/spenvis/ecss/ecss07/ecss07.html) with

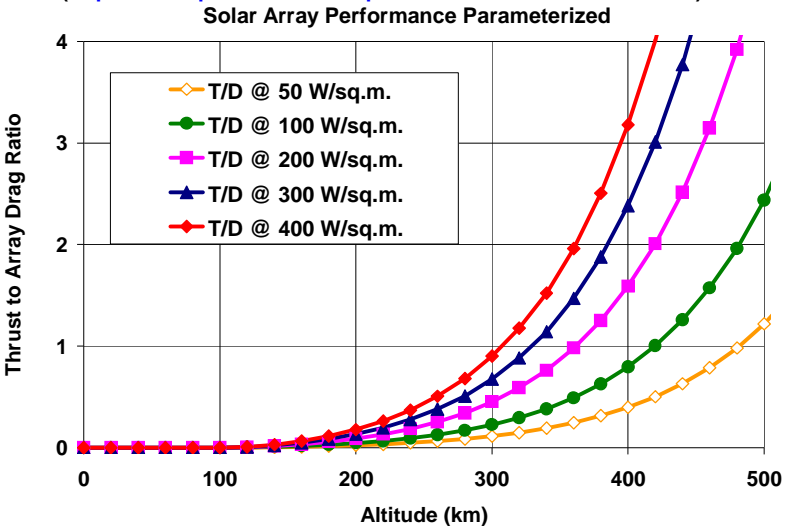

Fig. 8. SEP Tug Thrust to Drag Ratio in LEO.

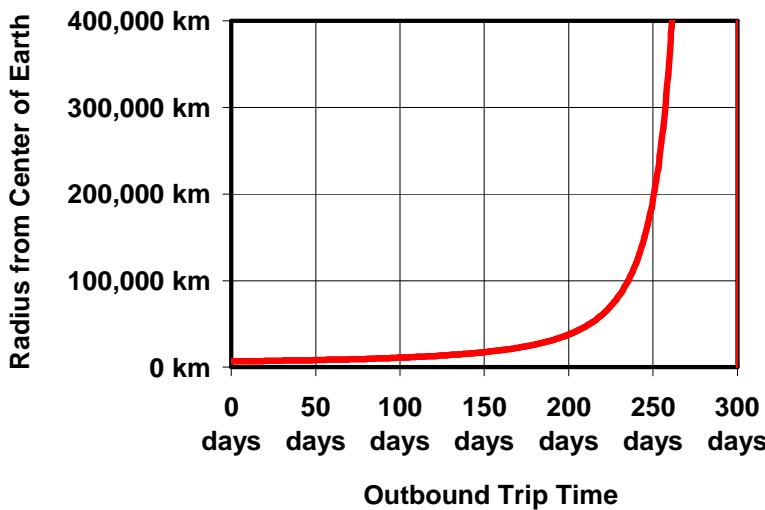

Fig. 9. SEP Tug Outbound Trajectory.

Radiation Shielding Optimization for 5 Round Trips of the SEP Lunar Tug with 2015 SLA Cells (39\% at 8 AMO Suns)

Cell Cover Glass Thickness (microns)

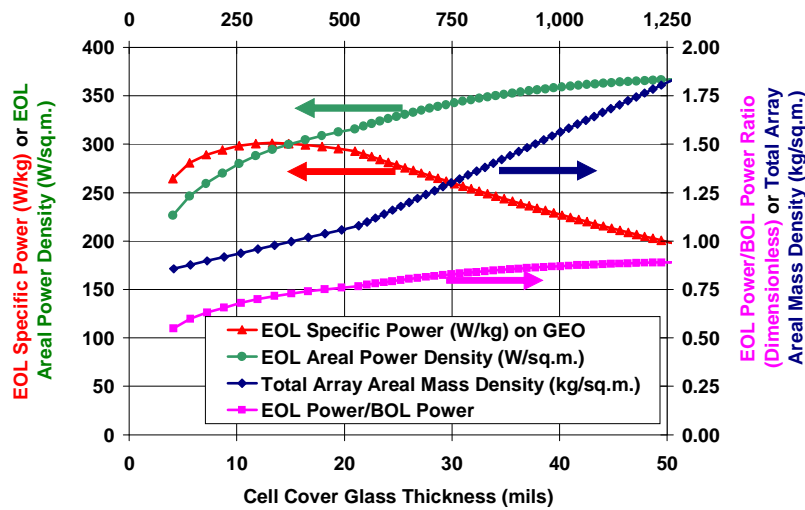

Fig. 10. Cell Shielding Optimization for the Mission.

function of solar cell cover glass thickness, and the corresponding solar cell power degradation for triplejunction cells, using again the European Space Agency's powerful online tool, SPENVIS, (www.spenvis.oma.be). The SPENVIS results are used to determine the optimal solar cell shielding for the SLASR array, with typical results summarized in Fig. 10. Note that the end-of-life (EOL) specific power has a peak value of $300 \mathrm{~W} / \mathrm{kg}$ corresponding to an optimal 375 microns ( 15 mils) of cell cover glass. These results are based on a future multijunction cell with a room-temperature efficiency at 8 AMO suns of $39 \%$ in 2015 . Today's SLASR cells have demonstrated $31 \%$ room-temperature efficiency, and multi-junction cells have averaged a $1 \%$ absolute efficiency gain per year for the past 20 years.

\section{FINANCIAL BENEFITS OF SLA-SEP SPACE TUG}

Table 2 shows the total launch mass and associated launch cost for delivering 110 MT of cargo to the lunar surface in support of exploration missions. The left half of the table corresponds to a conventional chemical propulsion approach. For the conventional system, the rocket equation was used to estimate propellant mass for the LEO to LLO trip, assuming a specific impulse of $400 \mathrm{sec}$ (the same as for the chemical lander rocket in Table 1) and a $\Delta V$ of $4 \mathrm{~km} / \mathrm{sec}$ (half the value for SEP in Table 1). The right half of the table corresponds to the SLASR-powered SEP approach detailed above, which offers more than $\$ 3$ billion in launch savings alone.

\begin{tabular}{|c|c|c|c|}
\hline \multicolumn{2}{|c|}{ Conventional Chemical Cargo Transport } & \multicolumn{2}{|c|}{ Reusable SLA-Powered SEP Cargo Transport } \\
\hline Item & Mass & Item & Mass \\
\hline $\begin{array}{l}\text { LEO-to-LLO Vehicle } \\
\text { (Expendable) }\end{array}$ & $7 \mathrm{MT}$ & LEO-to-LLO Vehicle (Reusable) & $7 \mathrm{MT}$ \\
\hline Cargo & $22 \mathrm{MT}$ & Cargo & $22 \mathrm{MT}$ \\
\hline Dry Lunar Lander & $5 \mathrm{MT}$ & Dry Lunar Lander & $5 \mathrm{MT}$ \\
\hline LLO-to-Lunar Surface Fuel & $18 \mathrm{MT}$ & LLO-to-Lunar Surface Fuel & $18 \mathrm{MT}$ \\
\hline LEO-to-LLO Fuel & $92 \mathrm{MT}$ & \begin{tabular}{|l} 
LEO-to-LLO Propellant (Xenon) \\
\end{tabular} & 26 MT \\
\hline & & Solar Array & $2 \mathrm{MT}$ \\
\hline Total Launch Mass & $144 \mathrm{MT}$ & $\begin{array}{c}\text { Total Launch Mass (First Launch } \\
\text { w/Vehicle) }\end{array}$ & $80 \mathrm{MT}$ \\
\hline & & $\begin{array}{c}\text { Total Launch Mass (Subsequent } \\
\text { Launches) }\end{array}$ & 73 MT \\
\hline $\begin{array}{c}\text { Total LEO Launch Mass for } \\
\text { Five Deliveries Over Five Years } \\
\text { (110 MT Total Cargo) }\end{array}$ & $720 \mathrm{MT}$ & $\begin{array}{c}\text { Total LEO Launch Mass for Five } \\
\text { Deliveries Over Five Years (110 } \\
\text { MT Total Cargo) }\end{array}$ & 372 MT \\
\hline $\begin{array}{l}\text { Launch Costs Using Shuttle- } \\
\text { Derived Heavy Launch Vehicle }\end{array}$ & $\$ 7,200$ Million & $\begin{array}{l}\text { Launch Costs Using Shuttle- } \\
\text { Derived Heavy Launch Vehicle }\end{array}$ & $\$ 3,720$ Million \\
\hline $\begin{array}{l}\text { (\$10 M/MT from ATK: } \\
\text { safesimplesoon.com) }\end{array}$ & & $\begin{array}{l}\text { (\$10 M/MT from ATK: } \\
\text { safesimplesoon.com) }\end{array}$ & \\
\hline
\end{tabular}

Table 2. SLA-SEP Tug Financial Benefits.

\section{ACKNOWLEDGEMENT}

The authors gratefully acknowledge NASA's support of the work presented in this paper.

\section{REFERENCES}

[1] Piszczor, M.F. and O'Neill, M.J., "Development of a Dome Fresnel Lens/GaAs Photovoltaic Concentrator for Space Applications," 19th IEEE Photovoltaic Specialists Conference (PVSC), New Orleans, 1987. [2] Curtis, H. and Marvin, D., "Final Results from the PASP Plus Flight Experiment," 25th IEEE PVSC, Washington, 1996.

[3] Murphy, D.M., "The SCARLET Solar Array: Technology Validation and Flight Results," Deep Space 1 Technology Validation Symposium, Pasadena, 2000.

[4] O'Neill, M.J., et al., "Development of the Ultra-Light Stretched Lens Array," 29th IEEE PVSC, New Orleans, 2002.

[5] O'Neill, M.J. et al., "Stretched Lens Array SquareRigger (SLASR) Technology Maturation," 19th Space Photovoltaic Research and Technology (SPRAT) Conference, Cleveland, 2005. 